\title{
West Nile Virus Seroprevalence Among Blood Donors in Hungary
}

\author{
Anna Nagy,, Tímea Szöllősi,, Mária Takács,, ${ }^{1,2}$ Nóra Magyar,, and Éva Barabás ${ }^{3}$
}

\begin{abstract}
Background and Objectives: West Nile virus (WNV) is one of the most important viral zoonotic infections in Hungary; however, no transfusion-transmitted WNV infections have been confirmed so far. In 2016, the number of clinical cases of WNV reported was 44, but the seasonal WNV screening of whole-blood donors has not yet been implemented. Our aims were to assess the WNV RNA reactivity and the prevalence of WNV-specific antibodies in the samples of blood donors collected in 2016.

Materials and Methods: WNV RNA with Cobas TaqScreen and anti-WNV antibody determination from plasma samples of 2112 donors was performed. Cross-reactivity to tick-borne encephalitis virus was excluded. WNV neutralization test was used for the confirmation of anti-WNV IgG reactive results, and the presence of anti-WNV IgM antibodies was also determined.

Results: None of the samples showed WNV RNA reactivity. The total weighted anti-WNV IgG prevalence was $2.34 \%$ (95\% confidence interval 1.65-3.03), and in addition, three donors were found to be IgM positive. There was a comparable tendency between the data of WNV seroprevalence and cumulative incidence in six out of seven statistical regions in Hungary.

Conclusion: Our results show a comparable data with publications that estimated the WNV seroprevalence in some other European endemic areas. As protective measures, both the 30-day deferral of blood donors who spent at least $24 \mathrm{~h}$ in WNV-exposed areas and the exclusion of affected Hungarian territories from blood donation are enforced by the Hungarian National Blood Transfusion Service. Our study is the first comprehensive serological survey to obtain actual data about WNV seroprevalence in the Hungarian human population.
\end{abstract}

Keywords: West Nile virus, blood donors, seroprevalence, Hungary

\section{Introduction}

W EST NILE VIRUS (WNV), a widely distributed member of the genus Flavivirus, family Flaviviridae, is responsible for numerous human and animal infections in Europe, Africa, and the Americas. WNV is a single-stranded RNA virus, which is divided into at least eight different genetic lineages (Kemenesi et al. 2014, Pachler et al. 2014). Lineage 1 and lineage $2 \mathrm{WNV}$ strains are considered the causative agents of both human and animal diseases (Barzon et al. 2015). Whereas the circulation of lineage 1 strains in Europe has long been known, lineage $2 \mathrm{WNV}$ strain was first detected outside of Africa in Hungary in 2004 (Bakonyi et al. 2006, Erdélyi et al. 2007, Papa 2017). However, most of the infections are asymptomatic; the severity of cases with clinical manifestation varies widely from the milder form of West Nile fever (WNF) to severe West Nile neuroinvasive disease (WNND), which can last from few weeks to even months. WNND could be characterized by meningitis, encephalitis, meningoencephalitis, encephalomyelitis, and/or polio-like acute flaccid paralysis (Hayes et al. 2005, Petersen et al. 2013, Barzon et al. 2015). Case fatality rate among patients with WNND is $\sim 10 \%$ (Petersen et al. 2013, Papa 2017). The predominance of neurological symptoms and fatal outcome is significantly higher in the older population, while immunocompromised patients with comorbidities such as malignancies or organ transplantation are also at higher risk of developing neuroinvasive disease (Ceccaldi et al. 2004, Kleinschmidt-DeMasters et al. 2004, Kumar et al. 2004, Ludlow et al. 2016).

\footnotetext{
${ }^{1}$ Department of Virology, National Public Health Institute (NPHI), Budapest, Hungary.

${ }^{2}$ Institute of Medical Microbiology, Semmelweis University, Budapest, Hungary.

${ }^{3}$ Confirmatory Laboratory, Hungarian National Blood Transfusion Service (HNBTS), Budapest, Hungary.
} 
WNV is primarily transmitted by Culex mosquitoes, however, infections related to blood transfusion and organ transplantation have been also described arising awareness of blood transfusion services to this possible way of virus transmission (Iwamoto et al. 2003, Pealer et al. 2003). WNV is one of the most important emerging arboviruses with an increasing number of human cases in Hungary, where the very first human neuroinvasive infections were reported in 2004 (Krisztalovics et al. 2008). No infections related to blood transfusion and organ transplantation have been described until now, and the seasonal WNV screening of wholeblood donors has not been implemented yet.

The laboratory diagnosis of human WNV infections across the whole country is performed at the National Reference Laboratory for Viral Zoonoses, National Public Health Institute (NPHI), Budapest, Hungary. The diagnostic algorithm includes different serological and molecular methods, as well as virus isolation. WNV infections are defined as laboratoryconfirmed or probable cases according to the European Union's case definition criteria (European Commission Implementing Decision, Brussels, 8.8.2012 C(2012) 5538).

Taking into account the serological cross-reactivity among the viruses of the genus Flavivirus, the interpretation of laboratory findings needs to be carefully considered in countries where at least two human pathogenic flaviviruses circulate (Calisher et al. 1989, Allwinn et al. 2002, Mansfield et al. 2011). Serological cross-reactions always have to be excluded against both tick-borne encephalitis virus (TBEV) and Usutu virus, which are also endemic flaviviruses in Hungary. It is important to note that primarily patients with severe clinical symptoms seek medical care. Therefore, mostly WNND cases are reported, while infections with milder symptoms or asymptomatic infections remain underrepresented.

In Hungary, the average annual number of laboratoryconfirmed or probable human infections is between 15 and 20. However, during the 2016 seasonal period, a significant increase was experienced with a total of 44 clinical cases (Krisztalovics et al. 2008, Szomor et al. 2011, European Centre for Disease Prevention and Control 2016). The peak of locally acquired cases was reported in the period from late August till mid-September. Regarding the unexpected number of cases, a pilot and prospective WNV PCR donor screening was enforced by the Hungarian National Blood Transfusion Service at the end of September 2016.The further increase in the number of autochthonous human cases during the subsequent 2 years $[n=21$ (2017) and $n=215$ (2018); European Centre for Disease Prevention and Control2017, 2018] highlights the public health concern of human WNV infections and the relevance of studies that provide current data regarding the WNV seroprevalence in the human population.

Although the diagnosed WNND cases cover almost the entire territory of the country, a comprehensive serological survey to gain information about the seroprevalence of WNV in the Hungarian human population has not been conducted since 2004. The single, retrospective seroepidemic study assessed the WNV seroprevalence performed at the NPHI in 2008, in samples collected from the general population in 1999.

The aims of the current study were to assess the presence of WNV RNA and anti-WNV antibodies in samples of wholeblood donors collected from territories with active virus circulation in Hungary during the 2016 transmission season.

\section{Materials and Methods}

\section{Blood donor samples}

Hungary is a Central-European country, which lies between latitudes $45^{\circ}$ and $49^{\circ} \mathrm{N}$ and longitudes $16^{\circ}$ and $23^{\circ} \mathrm{E}$, with a territory of $93,022 \mathrm{~km}^{2}(35,920 \mathrm{sq} \mathrm{mi})$. The Hungarian population was estimated at 9830.485 individuals in 2016 (Hungarian Central Statistical Office: Microcensus 2016). The Nomenclature of Territorial Units for Statistics (NUTS) designates seven statistical regions with two levels, including 19 counties and the capital city of Budapest (Table 1). Hungary is characterized by a well-centralized blood transfusion service. A single institute called the Hungarian National Blood Transfusion Service (HNBTS) operates two donor screening laboratories. Six NUTS 2 regions, comprising $81 \%$ of the whole territory, belong to the delivery area of the Central Screening Laboratory of HNBTS, Budapest $\left(47^{\circ} 49^{\prime} \mathrm{N}, 19^{\circ} 03^{\prime} \mathrm{E}\right)$, and the remaining $19 \%$ is subjected to the Screening Laboratory of HNBTS situated in Debrecen $\left(47^{\circ} 21^{\prime} \mathrm{N}, 21^{\circ} 37^{\prime} \mathrm{E}\right)$.

During the observed period from 28th September to 11th October, 2016, plasma samples of a total of 2112 voluntary

Table 1. West Nile Virus Seroprevalence Data of the Nomenclature of Territorial Units FOR STATISTICS 2 REgions in Hungary

\begin{tabular}{llcccc}
\hline & & \multicolumn{4}{c}{ Serosurvey among blood donors in 2016 } \\
\cline { 3 - 6 } $\begin{array}{l}\text { Statistical regions } \\
\text { at NUTS 2 level }\end{array}$ & $\begin{array}{c}\text { Donor screening } \\
\text { laboratory }\end{array}$ & Sample no. & $\begin{array}{c}\text { Proportion of } \\
\text { population (\%) }\end{array}$ & $\begin{array}{c}\text { Anti-WNV } \\
\text { positive no. }\end{array}$ & $\begin{array}{c}\text { Anti-WNV prevalence } \\
\text { (\%) with 95\% CI }\end{array}$ \\
\hline Central Hungary & CSL, Budapest & 893 & 0.030 & 20 & $2.24(1.45-3.43)$ \\
Central Transdanubia & CSL, Budapest & 405 & 0.038 & 8 & $1.98(1.00-3.85)$ \\
Western Transdanubia & CSL, Budapest & 214 & 0.022 & 2 & $0.93(0.26-3.34)$ \\
Southern Transdanubia & CSL, Budapest & 121 & 0.014 & 4 & $3.31(1.29-8.19)$ \\
Northern Hungary & CSL, Budapest & 146 & 0.013 & 1 & $0.69(0.12-3.78)$ \\
Northern Great Plain & SL, Debrecen & 73 & 0.005 & 2 & $2.74(0.75-9.45)$ \\
Southern Great Plain & CSL, Budapest & 252 & 0.02 & 9 & $3.57(1.89-6.65)$ \\
Overall (unweighted) & & 2104 & 0.02 & 46 & $2.19(1.64-2.90)$ \\
Total (weighted) & 2104 & 0.02 & 46 & $2.34(1.65-3.03)$ \\
\hline
\end{tabular}

CI, confidence interval; CSL, central screening laboratory; NUTS, Nomenclature of Territorial Units for Statistics; SL, screening laboratory; WNV, West Nile virus. 
whole-blood donors taking part in blood donations organized by the HNBTS were enrolled in the study.

Samples were selected randomly from the routine donor screening taking place in the Central Screening Laboratory of HNBTS in Budapest. All donor data were handled confidentially and anonymously, and all research protocols were approved by the institutional review boards.

\section{Donor demographics}

The sample size involved in this study was estimated to be $0.021 \%$ of the whole Hungarian population in 2016. The mean age of all donors was 38.4 years; the number of men and women was 1053 and 1059, respectively. The mean age of men was 40.2 years (ranging from 18 to 67 years) and of women was 36.7 years (ranging from 18 to 65 years). The number of first time and repeat blood donors was 378 and 1734, respectively.

Donor samples came from 45 donation municipalities and 437 residence settlements belonging to 6 and 7 NUTS 2 regions, respectively. The residential regions of 8 out of 2112 donors were not available, because 6 donors moved to unknown places and 2 individuals were foreigners. In the case of 1787 samples $(85 \%)$, there was a concurrence between donation and residence settlements at NUTS 2 level, however, $15 \%$ of these places were situated in distinct regions.

\section{Nucleic acid amplification test}

WNV PCR screening was conducted at the HNBTS, using the Cobas TaqScreen WNV test on a Cobas S201 system (Roche Diagnostics, Branchburg) in pools of six, following the instructions for users (IFU). A pool resolution to individual donation-nucleic acid amplification testing from the remaining primary tubes was the protocol in case of a reactive pool.

\section{Screening of the donor samples by indirect immunofluorescence assay and hemagglutination inhibition tests}

Serological assays were performed at the NPHI. First round anti-WNV IgG antibody screening was carried out with WNV immunofluorescence assay (IFA) developed inhouse (Szomor et al. 2011). Microscopic slides were coated with a mixture of WNV-infected and noninfected Vero cells. A tenfold dilution of a donor plasma sample in phosphatebuffered saline (PBS) was incubated on the slide at $4^{\circ} \mathrm{C}$, overnight. After incubation, microscopic slides were rinsed in PBS for 5 min. The washing step was repeated twice. For the visualization of antigen-antibody complexes, fluorescein isothiocyanate-conjugated polyclonal rabbit anti-human IgG antibodies (Dako Denmark; Glostrup, Denmark) were added. Before using, 1:90 dilutions of the fluorochrome-conjugated secondary antibodies were prepared in PBS. Incubation was carried out in the dark at $37^{\circ} \mathrm{C}$ for $30 \mathrm{~min}$. Microscopic slides were rinsed in PBS for three times, 5 min each. For covering the slides, glycerol PBS mounting medium and coverslips were used.

In case of each positive reaction, further testing to exclude serological cross-reactions had to be complied. Serial twofold dilutions of plasmas were enrolled and examined in parallel by IFA to determine the anti-WNV and anti-TBEV IgG endpoint titers. Cross-reactivity against TBEV was ruled out by com- paring the endpoint titers, where a significant, at least fourfold, difference between the anti-TBEV and anti-WNV antibody levels supported the evaluation of WNV seropositivity.

To strengthen the first round IFA results, hemagglutination inhibition (HI) tests were carried out to measure the antiWNV and anti-TBEV total antibody titers, following the protocol of Clarke et al., described in 1958.

\section{WNV neutralization test for confirmation}

All of the reactive plasmas were further examined by the WNV neutralization test (WNT). A WNV seropositive result was accepted only if it could be confirmed by WNT. Plasmas were inactivated at $56^{\circ} \mathrm{C}$ for $30 \mathrm{~min}$ and then fivefold diluted in cell culture medium (Medium 199; Sigma-Aldrich, SaintLouis). Serial twofold dilutions were prepared in 96-well microtiter plates, using Medium 199 in a $60 \mu \mathrm{L}$ final volume. Sixty microliters of 100 TCID $_{50}$ of WNV 578/10 strain (GenBank: KC496015, provided by Prof. Tamás Bakonyi, University of Veterinary Medicine, Budapest, Hungary) was added to each well and incubated at $4^{\circ} \mathrm{C}$, overnight. The next day, plates were incubated at $37^{\circ} \mathrm{C}$ for $1 \mathrm{~h}$, and $100 \mu \mathrm{L}$ of the mixture of the diluted plasmas and standard virus suspension was added to 96-well tissue culture plates covered with $80 \%$ confluent Vero cells. An additional 90-min incubation at $37^{\circ} \mathrm{C}$ allowed virus attachment, and then, a cell culture medium containing $5 \%$ fetal bovine serum was added to the final volume of $200 \mu \mathrm{L}$.

Microscopic evaluation of the cytopathic effect was carried out 3, 5, and 7 days after inoculation. Negative and seropositive human sera controls, negative cell controls, and back titration of the virus suspension in at least three rows were also applied. Furthermore, in case of each plasma sample, a plasma control was prepared to detect any possible cytotoxicity by adding $60 \mu \mathrm{L}$ of cell culture medium instead of virus suspension.

\section{Determination of anti-WNV IgM antibodies}

Anti-WNV IgM antibodies were determined in anti-WNV IgG or total antibody reactive samples using in-house IFA and WNV IgM Capture ELISA (Focus Diagnostics, Cypress) tests. For anti-WNV IgM, IFA testing plasmas were pretreated with Eurosorb absorbent (Euroimmun, Lübeck, Germany) to remove IgG molecules and IgM class rheumatoid factors. After incubation at room temperature for $15 \mathrm{~min}$, the test procedure was the same as described above, except using the rabbit anti-human IgM conjugate (Dako Denmark, Glostrup, Denmark). In case of WNV IgM Capture ELISA, the test procedure was carried out as described in the manufacturer's instruction.

\section{Statistics}

Seroprevalence was defined as a percentage of identified anti-WNV seropositivity in the study populations. Cumulative number of clinical cases was defined to include the WNV clinical cases registered in Hungary since 2004. Cumulative incidence was defined as a percentage of the cumulative number of reported clinical cases in the average general population between 2004 and 2016. Unweighted mean values, NUTS 2 region-specific seroprevalence, and cumulative incidence were calculated with the corresponding $95 \%$ 
confidence intervals (CIs) using the Wilson score interval method. Weighted mean with the weighting factor of the proportion of NUTS 2 population in the general population in the corresponding year was calculated. For the comparison of age and gender distribution between seropositive and seronegative groups, the Mann-Whitney nonparametric U-test and chi-squared test were applied, respectively. Statistical significance was defined at the level of $p<0.05$.

For visualization of geographical distribution, the European Center for Disease Prevention and Control Map Maker Tool (ECDC EMMa) was used. All calculations were performed by Microsoft Office Excel of Microsoft Office Professional Plus 2016 software and EpiTools epidemiological calculators (Ausvet Pty Ltd.) and SPSS Statistics v17.0 software. The sources of all population records applied in this study were the official data of Hungarian Central Statistical Office, Budapest, Hungary.

\section{Results}

\section{WNV PCR screening}

Based on the IFU, the estimated $95 \%$ limit of detection of WNV lineage 1 and lineage 2 was 36.9 and 3.8 copies $/ \mathrm{mL}$, respectively. None of pools of six showed reactivity on the Cobas 201 system with TaqScreen WNV nucleic acid test, since all individual samples should be considered nonreactive without the pool resolution protocol.

\section{Calculation of WNV seroprevalence in all sample sizes}

Among the 2112 plasmas evaluated for anti-WNV IgG antibodies, 393 donors were reactive in the initial in-house WNV IFA screening. All of the reactive plasmas were further tested by in-house TBEV IFA and gave unambiguously positive results in 267 samples, indicating anti-TBEV IgG seropositivity. Considering the parallel titration and the endpoint $\operatorname{IgG}$ antibody titers by IFA, from the remaining 126 reactive plasmas 71 samples were found to be anti-WNV IgG positive, while 55 plasmas resulted in equal anti-WNV and
anti-TBEV IgG levels. Total antibody titers were also assessed using $\mathrm{HI}$ where $55(2.6 \%)$ out of the 126 samples proved to be seropositive for WNV. Further verification by WNT confirmed WNV seropositivity in 46 donors (2.19\%). Among them, three samples $(6.52 \%)$ showed anti-IgM reactivity in both in-house IFA and commercial ELISA tests suggesting acute or recent WNV infections. In nine additional samples, besides the WNT seropositive results, there were similar titers of anti-WNV and anti-TBEV antibodies in IFA and/or HI test. The overall estimated unweighted prevalence of anti-WNV antibodies confirmed by WNT was $2.19 \%$ (95\% CI $1.64 \%-2.90 \%$ ). The total weighted prevalence adjusted by population proportions of NUTS 2 regions was $2.34 \%$ (95\% CI 1.65-3.03) (Table 1).

The mean age of the $46 \mathrm{WNV}$ seropositive blood donors was 41.2 years ranging from 18 to 67 years, 25 were men and 21 were women with the mean age of 42.2 and 39.9, respectively. There was no statistically significant difference between the age distribution of seropositive and seronegative donors $(p=0.113)$. By comparing the gender distribution between seropositive and seronegative donors, no significant difference was found $(p=0.538)$.

\section{Assessing of the territorial distribution of WNV seroprevalence}

For the subsequent analysis, donor samples were categorized by residential regions at NUTS 2 level. Altogether, 2104 samples were included into the calculation, and they could be divided into 7 NUTS 2 regions. The donor number was found to range from 73 to 893 with a proportion of $0.005 \%$ up to $0.038 \%$ in each NUTS 2 region (Table 1 ). The region of Northern Great Plain (NGP), which was out of the delivery area of the Central Screening Laboratory, showed the lowest number and proportion of donors (Table 1). The highest seroprevalence was calculated in Southern Great Plain (SGP) region $(3.57 \%)$, followed by Southern Transdanubia (STD) (3.31\%). NGP and Central Hungary $(\mathrm{CH})$ showed also high seroprevalence with $2.74 \%$ and $2.24 \%$, which were above the

FIG. 1. Geographical distribution of the WNV seroprevalence data in NUTS 2 regions in 2016 ( $p=$ seroprevalence; red asterisks indicate the residence settlements of anti-WNV IgMpositive donors). NUTS, Nomenclature of Territorial Units for Statistics; WNV, West Nile virus.

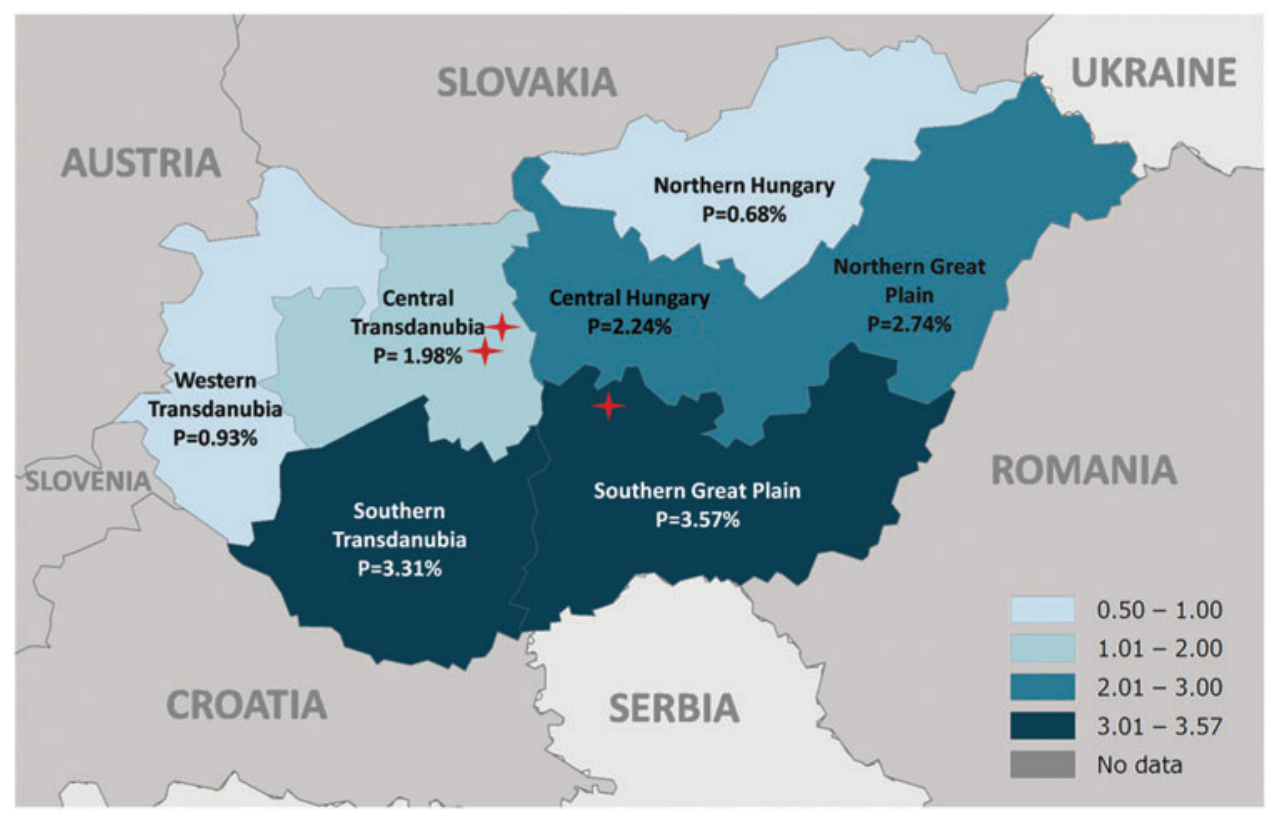


Table 2. Cumulative Incidence of West Nile Virus Clinical Cases Between 2004 and 2016

\begin{tabular}{lccr}
\hline $\begin{array}{l}\text { Statistical regions } \\
\text { at NUTS 2 level }\end{array}$ & $\begin{array}{c}\text { Average population } \\
\text { between 2004 and 2016 }\end{array}$ & $\begin{array}{c}\text { Cumulative no. } \\
\text { of clinical cases }\end{array}$ & $\begin{array}{c}\text { Cumulative incidence } \\
(\%) \text { with 95\% CI }\end{array}$ \\
\hline Central Hungary & $2,921,717$ & 66 & $0.0022(0.0018-0.0029)$ \\
Central Transdanubia & $1,091,368$ & 20 & $0.0018(0.0012-0.0028)$ \\
Western Transdanubia & 993,254 & 7 & $0.0007(0.0003-0.0015)$ \\
Southern Transdanubia & 944,999 & 7 & $0.0007(0.0004-0.0015)$ \\
Northern Hungary & $1,216,426$ & 11 & $0.0009(0.0005-0.0016)$ \\
Northern Great Plain & $1,505,145$ & 41 & $0.0027(0.0021-0.0037)$ \\
Southern Great Plain & $1,314,599$ & 48 & $0.0037(0.0028-0.0048)$ \\
Overall & $9,987,508$ & 200 & $0.0020(0.0017-0.0023)$ \\
\hline
\end{tabular}

mean value. There were three regions below the mean of the seroprevalence value: Central Transdanubia (CTD) with $1.98 \%$ and Western Transdanubia (WTD) and Northern Hungary (NH) with the seroprevalence of $0.93 \%$ and $0.69 \%$, respectively (Table 1 and Fig. 1).

Three out of the 46 reactive donors were found to be antiWNV IgM positive (6.52\%), and all of them were collected from regions with considerable WNV seroprevalence, from STD and CTD (Fig. 1).

\section{Comparison of geographical distribution between WNV seroprevalence data and the cumulative incidence of WNV clinical cases}

Between 2004 and 2016, altogether 200 laboratoryconfirmed and probable WNND or WNF clinical cases were diagnosed by the Hungarian National Reference Laboratory for Viral Zoonoses of the NPHI, which means $0.002 \% \mathrm{cu}-$ mulative incidence in the average population (Table 2). Taking into account the distribution of these cases, the region of SGP showed the highest WNV cumulative incidence with $0.0037 \%$, followed by $\mathrm{NGP}$ and $\mathrm{CH}$ with a prevalence of
$0.0027 \%$ and $0.0022 \%$, respectively. CTD showed a moderate prevalence with $0.0018 \%$, and there were three regions $\mathrm{NH}$, STD, and WTD much more below the mean of the reckoned prevalence value (Table 2 and Fig. 2).

The SGP region showed the highest seroprevalence as well as the highest cumulative incidence in clinical cases. In the case of six regions (CH, CTD, WTD, NH, NGP, and SGP), a correspondence could be observed between the rank of estimated seroprevalence in 2016 and the cumulative incidence of WNV cases between 2004 and 2016. In the STD region, the estimated low WNV cumulative incidence was not supported by the WNV seroprevalence (Tables 1 and 2 and Figs. 1 and 2).

\section{Discussion}

Compared with previous seasons in Hungary, a significant increase in the number of WNV clinical cases was recorded ( $n=44)$ during the 2016 transmission season. Based on the significant increase of the case number reported, the HNBTS enforced a pilot and prospective WNV NAT screening study among donors in the period from 28th September to 11th October. WNV-specific antibodies were also determined

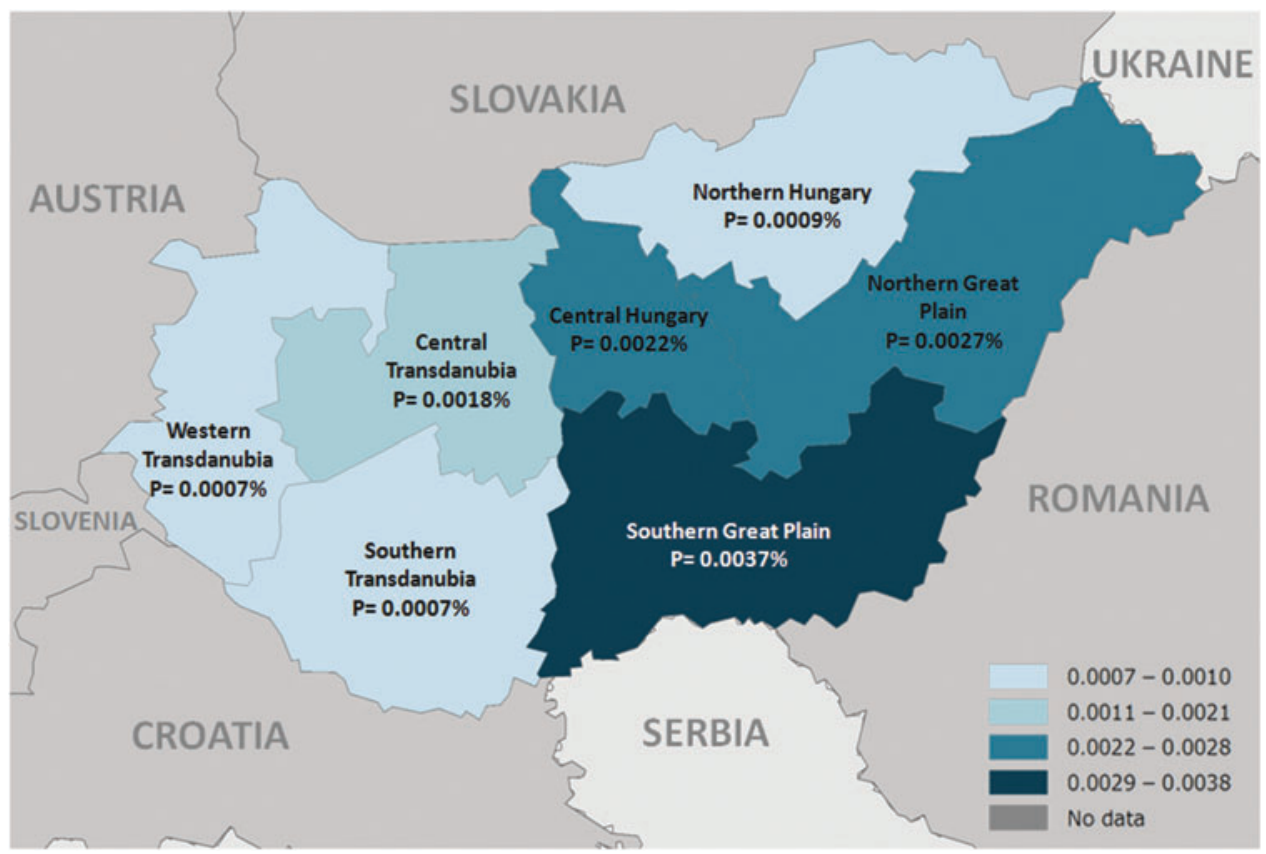

FIG. 2. Geographical distribution of the WNV cumulative incidence data based on the cumulative number of laboratory-diagnosed WNND and WNF cases in NUTS 2 regions between 2004 and 2016. CC, cumulative incidence; WNF, West Nile fever; WNND, West Nile neuroinvasive disease. 
from the donor samples. A total of 2112 randomly selected voluntary whole-blood donors were enrolled in the study from the delivery area of the Central Screening Laboratory of HNBTS, Budapest, which covered 6 out of 7 NUTS 2 regions. None of the samples showed reactivity in the PCR assay; however, anti-WNV antibody positivity could be detected with a $2.34 \%(95 \%$ CI $1.65 \%-3.03 \%)$ weighted total seroprevalence. Moreover, 3 out of 46 samples showed an additional anti-WNV IgM positivity suggesting acute or recent WNV infections.

The total weighted seroprevalence estimated in our recent study was significantly higher $(p=0.001)$ than that calculated in samples collected in 1999 (0.61\%, 95\% CI 0.00-1.2) (T. Szalkai, unpublished data).The former survey was conducted and verified by the same laboratory methods described in our present study, but samples were collected from the general population with a more extended age distribution.

According to the availability of residence settlements, 2104 donors could be involved in the subsequent analysis. Eighty-five percent of samples showed concurrence and $15 \%$ difference between donation and residence places at the NUTS 2 region level. In Hungary, bigger cities can serve as more favorable places of employment and education, and many people from smaller settlements, even from distinct regions, commute on a daily basis. Furthermore, preferred places for blood donation become special events, which can attract masses of people from their residence to other regions. These could be explanations for the distinction in donation and residential places and for the 73 donors whose residence settlements were situated in NGP, which was out of the delivery area of the Central Screening Laboratory.

After categorization of donors by residence NUTS 2 regions, a clear-cut ranking could be observed among the regions in the WNV seroprevalence (Table 1 and Fig. 1). Based on the two databases, SGP region indicated the highest WNV seroprevalence as well as WNV cumulative incidence (Tables 1 and 2 and Figs. 1 and 2). Moreover, this region showed the highest rate of clinical cases in 2004 when the first human WNV infections were confirmed in Hungary (data are not shown). Although a pretty good correlation could be observed between the estimated seroprevalence and the cumulative incidence in six regions $(\mathrm{CH}, \mathrm{CTD}, \mathrm{WTD}$, NH, NGP, and SGP), it should be analyzed with a limitation that the corresponding 95\% CI ranges are pretty extended (Tables 1 and 2 and Figs. 1 and 2). According to our current estimation, a higher cumulative incidence could have been expected in the case of STD (Tables 1 and 2 and Fig. 1-2). However, the NPHI serves as a nationwide reference center for arbovirus diagnostics; it should be considered that the territorial variations in the number of laboratory-confirmed acute infections may depend on the clinical examination and the demand for laboratory investigation.

Our recent results show fairly comparable data with recent publications estimating the WNV seroprevalence in some other European WNV endemic areas or countries. In Northern Italy, Pierro et al. identified $2.08 \%$ seroprevalence, while in Greece $2.1 \%$ IgG and $0.13 \%$ IgM and in Western Turkey $2.51 \%$ seropositivity was measured (Biçeroğlu et al. 2015, Pierro et al. 2013, Hadjichristodoulou et al. 2015). Comparing our new findings with the results of the retrospective survey carried out at the NPHI, WNV-estimated seroprevalence has significantly increased since 1999.

\section{Conclusions}

From the whole country, all probable WNV cases are officially notified to the HNBTS, where both donation and recipient activities of every WNV-infected individual will be checked. Until now, only one person has proved to be a blood donor without recent donation activity according to the database. Moreover, HNBTS strictly follows up seasonal WNV reports issued by the European Centre for Disease Prevention and Control (ECDC) fortnightly and has direct access to the EU rapid alert system that registers every WNV clinical case notified in any country on the European continent. According to these data, both 30-day deferral of whole-blood donors who spent at least $24 \mathrm{~h}$ in WNV-exposed areas and the exclusion of affected Hungarian territories from blood donation are enforced by HNBTS regularly.

The extraordinary increase in the number of reported clinical cases across eastern and central Europe and in the Mediterranean in 2018 highlighted the importance of implementation of timely response to reduce the transmission risk to humans via blood products. During the 2018 transmission season, the entire territory of Hungary became affected, including an area in the western part of the country where a human clinical case was reported for the first time. The significant difference that was experienced between the 1999 and recent seroprevalence data and the elevated transmission potential of WNV in connection with certain climate conditions have been raising awareness to implement an enhanced surveillance system in humans and vector control for measuring virus activity in Hungary.

These measures could contribute to the reconsideration of blood donation safety strategies, ensuring both recipient safety and the stable blood stock level in Hungary during the transmission season. Our recent study is the very first comprehensive serological survey in Hungary to obtain current data about WNV seroprevalence in the human population, since the first laboratory diagnosis of autochthonous Hungarian WNND cases in 2004.

\section{Acknowledgments}

Technical assistance provided by Magdolna T. Kaposi (NPHI), Nikolett Csonka (NPHI), Kornélia Financsek-Gál (HNBTS), Anita Tarjányi (HNBTS), and Judit Magyar (HNBTS) is greatly appreciated by the authors. They thank W. Kurt Roth for critical reviewing and suggestions for improvement, Jozsef Baricsa for language reviewing, and Gyula Lepcsényi for downloading of donation records.

\section{Author Disclosure Statement}

No competing financial interests exist.

\section{References}

Allwinn R, Doerr H, Emmerich P, Schmitz H, et al. Crossreactivity in flavivirus serology: New implications of an old finding? Med Microbiol Immunol 2002; 190:199-202.

Bakonyi T, Ivanics É, Erdélyi K, Ursu K, et al. Lineage 1 and 2 strains of encephalitic West Nile virus, Central Europe. Emerg Infect Dis 2006; 12:618-623.

Barzon L, Pacenti M, Ulbert S, Palú G. Latest developments and challenges in the diagnosis of human West Nile virus infection. Expert Rev of Anti Infect Ther 2015; 13:327-342. 
Biçeroğlu SU, Karatayli E, BayramA, Turhan A, et al. Investigation of West Nile virus among healthy blood donors in the western part of Turkey. Turk J Med Sci 2015; 45:84-88.

Calisher CH, Karabatsos N, Dalrymple JM, Shope RE, et al. Antigenic relationships between flaviviruses as determined by cross-neutralization tests with polyclonal antisera. J Gen Virol 1989; 70:37-43.

Clarke DH, Casals J. Techniques for hemagglutination and hemagglutination-inhibition with arthropod-borne viruses. Am J Trop Med Hyg 1958; 7:561-573.

Ceccaldi PE, Lucas M, Despres P. New insights on the neuropathogenicity of West Nile virus. FEMS Microbiol Lett 2004; 233:1-6.

European Centre for Disease Prevention and Control. Epidemiological update: West Nile virus transmission season in Europe, 2016. Available at https://ecdc.europa.eu/en/newsevents/epidemiological-update-west-nile-virus-transmissionseason-europe-2016

European Centre for Disease Prevention and Control. Epidemiological update: West Nile virus transmission season in Europe, 2017. Available at https://ecdc.europa.eu/en/newsevents/epidemiological-update-west-nile-virus-transmissionseason-europe-2017

European Centre for Disease Prevention and Control. Weekly updates: 2018 West Nile fever transmission season. Available at https://ecdc.europa.eu/en/west-nile-fever/surveillance-anddisease-data/disease-data-ecdc

European Commission Implementing Decision, Brussels, 8.8.2012 C(2012) 5538. Available at https://www.fhi.no/globalassets/ dokumenterfiler/helseregistre/nois/ecdcs-kasusdefinisjonerfullstendig-engelsk-versjon-av-kasusdefinisjonene-avsmittsomme-sykdommer-august-2012-pdf-.pdf

Erdélyi K, Ursu K, Ferenczi E, Szeredi L, et al. Clinical and pathologic features of lineage 2 West Nile virus infections in birds of prey in Hungary. Vector Borne Zoonotic Dis 2007; 7: 181-188.

Hadjichristodoulou C, Pournaras S, Mavrouli M, Marka A, et al. West Nile Virus seroprevalence in the Greek population in 2013: A Nationwide Cross-Sectional Survey. PLoS One 2015; 10:e0143803.

Hayes EB, Sejvar JJ, Zaki SR, Lanciotti RS et al. Virology, pathology, and clinical manifestations of West Nile virus disease. Emerg Infect Dis 2005; 11:1174-1179.

Hungarian Central Statistical Office: Microcensus 2016. 2. Main characteristics of the population and the dwellings. 3.1 Data on counties/Data on districts. Available at https://www.ksh.hu/ mikrocenzus2016/book_2_characteristics_of_population_and_ dwellings
Iwamoto M, Jernigan DB, GuaschA, Trepka MJ, et al. Transmission of West Nile virus from an organ donor to four transplant recipients. N Engl J Med 2003; 348:2196-2203.

Kemenesi G, Dallos B, Oldal M, Kutas A, et al. Putative novel lineage of West Nile virus in Uranotaenia unguiculata mosquito, Hungary. Virus Dis 2014; 25:500-503.

Kleinschmidt-DeMasters BK, Marder BA, Levi ME, Laird SP, et al. Naturally acquired West Nile virus encephalomyelitis in transplant recipients. Arch Neurol 2004; 61:1210-1220.

Krisztalovics K, Ferenczi E, Molnár Z, Csohán Á, et al. West Nile virus infections in Hungary, August-September 2008. Euro Surveill 2008; 13:19030.

Kumar D, Prasad GVR, Zaltzman J, Levy GA, et al. Community-acquired West Nile virus infection in solid-organ transplant recipients. Transplantation 2004; 77:399-402.

Ludlow M, Kortekaas J, Herden C, Hoffmann B, et al. Neurotropic virus infections as the cause of immediate and delayed neuropathology. Acta Neuropathol 2016; 131:159-184.

Mansfield KL, Horton DL, Johnson N, Li L, et al. Flavivirusinduced antibody cross-reactivity. J Gen Virol 2011; 92: 2821-2829.

Pachler K, Lebl K, Berer D, Rudolf I, et al. Putative new West Nile virus lineage in Uranotaenia unguiculata mosquitoes, Austria, 2013. Emerg Infect Dis 2014; 20:2119-2122.

Papa A. Emerging arboviral human diseases in Southern Europe. J Med Virol 2017; 89:1315-1322.

Pealer LN, Marfin AA, Petersen LR, Lanciotti RS, et al. Transmission of West Nile virus through blood transfusion in the United States in 2002. N Engl J Med 2003; 349:12361245.

Petersen LR, Brault AC, Nasci RS. West Nile Virus: Review of the Literature. JAMA 2013; 310:308-315.

Pierro A, Gaibani P, Spadafora C, Ruggeri D, et al. Detection of specific antibodies against West Nile and Usutu viruses in healthy blood donors in northern Italy, 2010-2011. Clin Microbiol Infect 2013; 19:945-947.

Szomor K, Rigó Z, Bán E, Nagy L, et al. Serologic evidence of West Nile virus infection in patients with exanthema in Hungary. Acta Microbiol Immunol Hung 2011; 58:157-167.

Address correspondence to: Éva Barabás Hungarian National Blood Transfusion Service (HNBTS) Karolina Street 19-21 Budapest H-1113 Hungary

E-mail: barabas.eva@ovsz.hu 